\title{
How to Summarize a 6,000-Word Paper in a Six-Minute Video Clip
}

\section{Comment résumer un texte de 6000 mots en une vidéo de six minutes}

\author{
$\sqrt{3}$ \\ PASCALE LEHOUX, PHD \\ Professor, Department of Health Administration, University of Montreal \\ Institute of Public Health Research, University of Montreal (IRSPUM) \\ Canada Research Chair on Health Innovations \\ Montreal, QC \\ PATRICK VACHON \\ Multimedia Technician, Institute of Public Health Research, University of Montreal (IRSPUM) \\ Montreal, QC \\ GENEVIEVE DAUDELIN, PHD \\ Research Assistant, Institute of Public Health Research, University of Montreal (IRSPUM) \\ Montreal, QC \\ MYRIAM HIVON, PHD \\ Research Assistant, Institute of Public Health Research, University of Montreal (IRSPUM) \\ Montreal, QC
}

\begin{abstract}
As part of our research team's knowledge transfer and exchange (KTE) efforts, we created a six-minute video clip that summarizes, in plain language, a scientific paper that describes why and how three teams of academic entrepreneurs developed new health technologies. Recognizing that video-based KTE strategies can be a valuable tool for health services and policy researchers, this paper explains the constraints and sources of inspiration that shaped our video production process. Aiming to provide practical guidance, we describe the steps and tools that we used to identify, refine and package the key content of the scientific paper into an original video format.
\end{abstract}




\section{Résumé}

Dans le cadre des initiatives de transfert et d'échange de connaissances (TEC) de notre équipe de recherche, nous avons produit une vidéo de six minutes qui résume, en langage simple, un article scientifique décrivant pourquoi et comment trois équipes d'entrepreneurs universitaires ont développé de nouvelles technologies de la santé. Tout en reconnaissant que la vidéo constitue une stratégie de TEC valable pour les chercheurs en services et politiques de santé, cet article décrit les contraintes et les sources d'inspiration qui ont entouré la production de notre vidéo. En guise de guide pratique, nous décrivons les étapes et outils que nous avons employés pour déterminer, affiner et formuler le contenu clé de l'article scientifique en un format vidéo original.

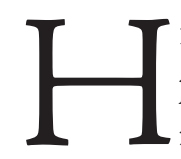

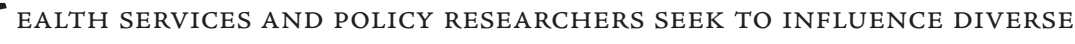
professional, policy and non-expert communities that may never have access to research findings in the form of scientific papers. Because audio-visual material can convey complex arguments and trigger new reflections (Harrison 2002), we developed a sixminute video clip as part of our integrated knowledge transfer and exchange (KTE) efforts. Within the context of a workshop, our goal was to foster productive deliberations by health technology developers, clinicians and patient representatives. Our video clip summarizes, in plain language, the key findings of a qualitative study that describes the process by which three teams of academic entrepreneurs each developed a new technology: a cardiac ablation catheter, a labour decision support software application and a home monitoring system (Lehoux et al. 2011). While technology developers, clinicians and patient representatives influence, and are influenced by, the development of new medical technologies, they may not share a common understanding of the issues at hand and may also lose sight of the "bigger picture" when it comes to technological development in healthcare. For an audience that may not be reached by scientific communication channels (e.g., healthcare providers, patients), our video clip provides an opportunity to ponder the broader implications of three different approaches to the design of medical technologies: "Building, Assembling, Adapting" (see video, in French): http:// vimeo.com/48372194.

Since health services and policy researchers are increasingly involved in KTE and interested in novel communication strategies (Straus et al. 2009), this paper explains the key constraints and sources of inspiration that nourished our video production process. Our goal being to provide practical guidance, we describe the KTE approach that we adopted, along with the steps and tools that we used to iteratively identify, refine and package our key messages into an original video clip.

\section{Overall KTE Approach and Sources of Inspiration}

While those who develop medical devices make several assumptions on behalf of clinicians, 
patients and society as a whole (about their feasibility as well as their relevance), they rarely question why and how such technologies are being developed, and whether these technologies are synergistic with healthcare systems' goals. We produced this KTE-oriented video clip in order to explore such complex issues with a mixed audience at an invitational workshop, which we hosted in Montreal on June 15, 2012. Combining multimedia tools and smallgroup discussions, this workshop was a rare opportunity for clinicians, technology designers and patient representatives to debate policy issues pivotal to the sustainability of healthcare systems (see the program: http://www.medsp.umontreal.ca/crcinnovations/TechMed2012/ TechMed2012.html).

In discussions within heterogeneous groups, audio-visual material can be a particularly effective medium for increasing the reactivity of participants because it puts "images to work" while sharing knowledge on matters with which some participants may be less familiar (Harrison 2002). Such audio-visual elicitation-based KTE material can help participants articulate their views and acknowledge differences between individual perspectives. We adopted the perspective of Golden-Biddle and colleagues (2003: 21), which emphasizes the "communicative elements called upon in knowledge making and using efforts." Because specialization and disciplinary frameworks often limit the quality and depth of discussions within mixed audiences (Denis et al. 2004), our team sought to facilitate the ability of "each party to translate between, and at least partially integrate, their own and the others' frameworks" (Bartunek et al. 2003: 66).

To create a lively and informal video, our team tapped into various sources of inspiration and input (see Acknowledgements). While a few scientific journals and research institutes have begun to integrate videos as web-based supplemental information, most of these initiatives replicate conventional scientific communication practices (e.g., videos of conferences, expert interviews or panels). Equally misaligned with our KTE aim are the tone and structure of science popularization documentaries, which are explicitly geared to "educating" a nonexpert audience and tend to put scientists centre stage.

We therefore turned our attention to other types of video. Of particular interest were those produced by RSA, a charity based in the United Kingdom, whose "purpose is to develop and promote new ways of thinking about human fulfilment and social progress" (http:// www.thersa.org). In our opinion, the RSA Animate videos are truly exceptional in their ability to convey complex arguments while being visually captivating. Some of their videos have been seen 10 million times on YouTube. They use animated hand drawings that schematize key arguments made by a speaker who never appears on screen (voice-over). Our creative process was also informed by academic initiatives that seek to involve members of the public in deliberations about technological developments (Boenink et al. 2010). A consortium led by the Norwegian Centre for the Study of the Sciences and the Humanities at the University of Bergen recently completed the Technolife project (http://www.technolife.no), which combined audio-visual and online tools. These videos rely on both static and dynamic images, including interventions by actors who personify, for instance, the chief executive officer of a company or a scientist. 
These are only a few of the examples that inspired our team and shaped our decisions regarding what techniques to use. While we were seduced by the RSA Animate videos, using this technique would have required too great an investment in human and financial resources. Overall, we felt that our message did not require complex visual support, but that our qualitative study findings (i.e., three stories of technological development) would lend themselves to a personal engagement with the audience. We thus decided to combine animation with actors to personify three academic entrepreneurs and a "researcher-narrator" (the first author).

\section{Tools to Support the Production Process}

Producing a video requires tight control of (a) what is said, (b) what is shown visually and (c) how the combination of what is said/shown visually unfolds. Accordingly, three tools were pivotal in moving our creative process forward. The first was a script organizing the information and key messages contained in the scientific paper into a continuous flow (i.e., a narrative). While this script was repeatedly condensed, revised and modified, it offered a template with clear boundaries. The amount of information that could be effectively conveyed in a six-minute video clip is limited. Table 1 summarizes our distillation process and the lessons learned. Established principles in KTE, such as identifying the messages that should be transferred, those to whom it should be directed and how, and the potential effects (Lavis et al. 2003), were an indispensable starting point. However, writing the script involved considerable trade-offs. In order to tell the three technological stories that are described in the paper, we had to choose carefully which empirical observations to include. While trying not to oversimplify our scholarly endeavour, we used concepts that are, from a communication standpoint, easily graspable (e.g., worlds, lenses) and abandoned those requiring a fuller explanation (i.e., modalities of engagement). The script enabled us to swiftly record audio tests (using the Microsoft Word "memo" function), which enhanced the clarity and readability of the script, forcing our team to focus on what would be said rather than being distracted by what would be shown.

The second tool was a storyboard showing the visuals that would accompany the script. We used PowerPoint because it enabled us to play with the images and text that might illustrate each sequence of the script. Discussing this storyboard with the team not only generated many new ideas, but also allowed us to troubleshoot parts of the script that were not working properly. The ability to test different visuals rapidly was pivotal. Both animation and video editing are time-consuming. Hence, the sooner one can estimate, even roughly, the number of hours that will be required to create a given number of seconds of video, the better. The storyboard also enabled our team to explore how varying spatial arrangements on the screen and text colour schemes could facilitate comprehension of our key points. This simple visual communication tool provided a structure for organizing the three empirical stories and the points being made by the researcher-narrator. The actors were shown both the final script and the storyboard (available upon request), and they were also given general cues about the characters they were personifying. 
TABLE 1. Lessons learned during the process of identifying and distilling the paper's key messages

\begin{tabular}{|c|c|}
\hline Steps in Writing the Script & Lessons Learned \\
\hline $\begin{array}{l}\text { I. Three co-authors independently extracted all the messages } \\
\text { contained in the paper with respect to: } \\
\text { - Background to the study } \\
\text { - Purpose of the study } \\
\text { - } \quad \text { Implings (the three cases of technology development) } \\
\text { - Implions of the study }\end{array}$ & $\begin{array}{l}\text { - Many team discussions regarding the key messages and } \\
\text { implications of our case study were necessary } \\
\text { - Our team needed external input and communication expertise } \\
\text { because we were "too close" to our research findings }\end{array}$ \\
\hline $\begin{array}{l}\text { 2. Gathered external input and feedback regarding how the } \\
\text { "story should be told" to a non-specialized audience (see } \\
\text { Acknowledgements) }\end{array}$ & $\begin{array}{l}\text { - While we did not follow all the advice we gathered, seeking } \\
\text { external input helped us clarify the trade-offs that would be } \\
\text { necessary } \\
\text { - Pondering which concepts were useful from a communication } \\
\text { standpoint was pivotal } \\
\text { - Realizing that the scientific structure of the paper should be } \\
\text { abandoned was an eye-opener; it enabled us to envision a } \\
\text { different way of telling the "story" }\end{array}$ \\
\hline 3. Developed a "one-pager" with the key messages & $\begin{array}{l}\text { - Establishing a hierarchy between primary and secondary } \\
\text { messages helped us identify the most salient messages }\end{array}$ \\
\hline 4. Drafted and refined iteratively the script (tool $\# I$ ) & $\begin{array}{l}\text { Realizing that some empirical details and nuances were not } \\
\text { essential to illustrating the key dynamics of the three empirical } \\
\text { cases helped us to streamline the script }\end{array}$ \\
\hline
\end{tabular}

The third tool was a sequence-by-sequence shooting plan. This was created after repeated adjustments were made to the storyboard and the script in order to better articulate the key messages. The shooting plan was created by our multimedia expert (PV) and contained very detailed information regarding the positioning of the camera and the movements of the visuals (animation and text). It not only provided precise information about what should precede and follow each scene (for instance, how many seconds the comedian should remain still), but also served as a "roadmap" for coordinating all of the tasks of team members on the day of shooting (e.g., positioning and testing of microphones, holding prompts and moving the lighting system). That being said, some room was left to allow for deviating from this plan. Continuous feedback from team members and the actors led us to modify some passages in the script during the shooting. Not surprisingly, several takes were needed to obtain high-quality audiovisual material; it took almost seven hours of shooting to create our six-minute video.

\section{Constraints that Fuelled the Creative Process}

Table 2 summarizes the key steps that helped coordinate our team efforts from the pre- to post-production stage. Although software and multimedia tools for making high-quality videos are becoming increasingly accessible to the non-expert, technical expertise is required. Researchers who wish to create videos should involve a multimedia expert throughout the process because both format and content influence each other. In our experience, engaging in the process as a team - valuing one another's contributions and appraising together the strengths and weaknesses of diverse solutions - is of paramount importance. 
TABLE 2. The steps and tools that helped coordinate our team efforts from the pre- to post-production stage

\begin{tabular}{|c|c|}
\hline \multicolumn{2}{|c|}{ Pre-Production } \\
\hline Content: & Format: \\
\hline $\begin{array}{l}\text { I. Following the steps described in Table I, write and revise the } \\
\text { script: Tool \# I "the story to tell" }\end{array}$ & $\begin{array}{l}\text { - Define the constraints: length, resources available, technical } \\
\text { requirements and capacity, etc. }\end{array}$ \\
\hline $\begin{array}{l}\text { 2. Obtain feedback from various perspectives (see } \\
\text { Acknowledgements) }\end{array}$ & - Define artistic direction (what should the video look like?) \\
\hline $\begin{array}{l}\text { 3. Test the vocal delivery of the script through audio recordings } \\
\text { (How well does it flow? At what pace should the delivery } \\
\text { unfold?) }\end{array}$ & $\begin{array}{l}\text { - Sketch and revise the storyboard: Tool \#2 - the script is } \\
\text { broken down into separate sequences with visual cues for what } \\
\text { will be shown as the story unfolds }\end{array}$ \\
\hline $\begin{array}{l}\text { 4. Recruit and provide guidance to the actors and researcher- } \\
\text { narrator }\end{array}$ & $\begin{array}{l}\text { - Test technical solutions (lighting and shooting methods, special } \\
\text { effects, transitions, rough animations, feasibility) } \\
\text { - Create the sequence-by-sequence shooting plan: Tool \#3- } \\
\text { a production master plan for turning the storyboard into reality } \\
\text { - Review with team members the shooting order, camera } \\
\text { placement and movements, transitions, etc., making sure that } \\
\text { all sound/images needed will be recorded } \\
\text { - Secure equipment, set up the shooting space and lighting, find } \\
\text { accessories, prepare cue cards }\end{array}$ \\
\hline \multicolumn{2}{|c|}{ Production (Shooting) } \\
\hline \multicolumn{2}{|c|}{ Coordination of each team member's roles and tasks by the director (camera, audio, assistant director, prompter, production assistant) } \\
\hline \multicolumn{2}{|c|}{ Provide delivery instructions and guidance to the actors and researcher-narrator } \\
\hline \multicolumn{2}{|c|}{ For each scene, do several takes in order to obtain the best one in terms of video/audio quality and delivery } \\
\hline \multicolumn{2}{|c|}{ Post-Production } \\
\hline Editing: & Dissemination: \\
\hline I. Review and select the best shots & - Prepare and host a first public viewing \\
\hline 2. Create animation sequences & - Prepare the web delivery of the video clip \\
\hline 3. Create music and audio mix & - Develop a "two-liner" to introduce the video clip \\
\hline 4. Add special effects, titles and end credits & $\begin{array}{l}\text { - Identify relevant electronic distribution lists and send the } \\
\text { announcement }\end{array}$ \\
\hline 5. Final review with team members & $\begin{array}{l}\text { - Identify relevant venues for small-group discussions (workshop, } \\
\text { brown bag session) or interactive web postings }\end{array}$ \\
\hline
\end{tabular}

We found that constraints related to content, video format or both often acted as a stepping stone, pushing us to find creative solutions. When we were writing the script, the key challenge was concision. We succeeded in overcoming this challenge only when, with the help of communication experts, we realized that the structure of the paper (i.e., background, conceptual framework, methods, results, discussion and conclusion) could and should be dropped. It was also a challenge having actors personify actual study participants. We found this approach appealing because it reinforces the fact that medical technology is designed by people who make decisions on behalf of clinicians and patients. However, it also introduced 
an ethical issue: viewers might believe that the actors appearing on screen were the individuals that we interviewed anonymously for the study. This constraint led to a creative solution: the silhouette technique. This concealed the identity of the actors while invoking real persons whose anonymity was preserved (a strategy akin to the use of pseudonyms in qualitative research).

\section{What Was Left Out, and What Lies Ahead}

Creating a six-minute video clip that summarizes a 6,000-word scientific paper implies putting aside a researcher's conceptual and methodological armamentarium and some of the empirical subtleties and contextual nuances of a qualitative study. While addressing the likely impact of video-based KTE falls beyond the scope of this paper, according to data collected at the end of our workshop, on a five-level Likert-type scale, the majority of the participants who completed the survey $(n=17 ; 90 \%$ response rate) gave a score of 4 or 5 to the following items: the videos "generated interest" (82\%); "contributed to their knowledge" (71\%); "contained clear messages" (77\%); and "addressed important issues" (88\%). Records from Vimeo and Google Analytics indicate around 220 views since September 2012. While dissemination strategies that tap into small-group discussions (e.g., "brown bag lunch" sessions) or interactive web platforms (e.g., blogs) seem logically adapted to the kind of video we created, there is a need for comparative studies. For instance, would there be types of study design (or research findings) that should instead be summarized in shorter clips, with clear "actionable" messages, and aiming at swift, "viral-like" dissemination? Alternatively, would there be studies that would mainly require a one-page summary for their findings to be put into action?

Many challenges thus lie ahead, as the knowledge base remains limited. Continuing experimentation with video-based KTE activities by researchers, including the application of the process and tools described in this paper, could eventually fill some important gaps in communication and knowledge transfer. In many areas, there is a need for communication tools that can help multiple stakeholder groups understand one another's role in the "bigger picture" of healthcare management and policy. Furthermore, one is forced to recognize that most scientific papers will never be read by the professional, policy and non-expert communities that health services and policy researchers are trying to inform or influence through their research. Ultimately, engaging in non-traditional KTE exercises can help consolidate researchers' ability to communicate complex research-based arguments.

\section{Acknowledgements}

We would like to thank Jean-Louis Denis, Bryn Williams-Jones, Fiona A. Miller, David Urbach and Christopher Longo, co-investigators in the research program within which this KTE initiative took shape. Marie Lambert-Chan, a journalist at University of Montreal, Ève Caroline Pomerleau, a documentary filmmaker, and Oliver Demers-Payette, a $\mathrm{PhD}$ candidate at University of Montreal, provided helpful criticism on early versions of the script. We are grateful to the theatre company Les Veilleurs de nuit for its enthusiasm towards this project, 
and to its actors, whose dedication and insightful observations proved to be invaluable on the day of shooting. We also thank two anonymous reviewers for their feedback on a previous version of the manuscript.

The workshop and production of two video clips were funded by an operating grant from the Canadian Institutes of Health Research (CIHR; \#KTB-1143). P. Lehoux holds a Canada Research Chair on Health Innovations (2010-2015). Our research group infrastructure is supported by the Fonds de la recherche en santé du Québec (FRSQ).

Correspondence may be directed to: Pascale Lehoux, PhD, Professor, Department of Health Administration, University of Montreal, P.O. Box 6128, Branch Centre-ville, Montreal, Quebec, H3C 3J7; tel.: 514-343-7978; fax: 514-343-2448; e-mail: pascale.lehoux@umontreal.ca.

\section{References}

Bartunek, J., J. Trullen, E. Bonet and A. Sauquet. 2003. “Sharing and Expanding Academic and Practitioner Knowledge in Health Care." Journal of Health Service Research and Policy 8(Suppl. 2): 62-68.

Boenink, M., T. Swierstra and D. Stemerding. 2010. “Anticipating the Interaction between Technology and Morality: A Scenario Study of Experimenting with Humans in Bionanotechnology." Studies in Ethics, Law and Technology 4(2). doi: 10.2202/1941-6008.1098.

Denis, J.-L., P. Lehoux and F. Champagne. 2004. “Knowledge Utilization in Health Care: From Fine-Tuning Dissemination to Contextualizing Knowledge." In L. Lemieux-Charles and F. Champagne, eds., Using Knowledge and Evidence in Health Care: Multidisciplinary Perspectives. Toronto: University of Toronto Press.

Golden-Biddle, K., T. Reay, S. Petz, C. Witt, A. Casebeer, A. Pablo and B. Hinings. 2003."Towards a Communicative Perspective of Collaborating in Research: The Case of the Researcher-Decision-Maker Partnership." Journal of Health Service Research and Policy 8(Suppl. 2): 20-25.

Harrison, B. 2002. "Seeing Health and Illness Worlds: Using Visual Methodologies in a Sociology of Health and Illness: A Methodological Review." Sociology of Health E Illness 24: 856-72.

Lavis, J., D. Robertson, J. Woodside, B. McLeod, J. Abelson and the Knowledge Transfer Study Group. 2003. “How Can Research Organizations More Effectively Transfer Research Knowledge to Decision-Makers?" Milbank Quarterly 81(2): 221-48.

Lehoux, P., M. Hivon, B. Williams-Jones and D. Urbach. 2011.“The Worlds and Modalities of Engagement of Design Participants: A Qualitative Case Study of Three Medical Innovations." Design Studies 32(4): 313-32.

Straus, S., J. Tetroe and I. Graham. 2009. Knowledge Translation in Health Care: Moving from Evidence to Practice. Singapore: Wiley-Blackwell Publishing. 